\title{
Micro-morphological Models for the Special Wettability of Locust and Moth Wing
}

\author{
Yan Fang ${ }^{a}$, Gang Sun ${ }^{b}$, Jing Wang $^{c}$, Yongfang Hou ${ }^{d}$, Dandan Jin $^{\mathrm{e}}$ and Luming \\ Baif $^{\dagger}$
}

School of Life Science, Changchun Normal University, Changchun 130032, China

afangyan124@aliyun.com, ${ }^{b}$ sungang@nenu.edu.cn, ${ }^{\text {jjing6456@163.com, }{ }^{d} 2397003691 @ q q . c o m, ~}$ '751599002@qq.com, ${ }^{\mathrm{f}} 15754320455 @ 163 . c o m$

\begin{abstract}
The microstructure, hydrophobicity and chemical composition of the moth and locust wing surfaces were investigated by a scanning electron microscope (SEM), a video-based contact angle (CA) meter and a Fourier transform infrared spectrometer (FT-IR). The hydrophobicity models were established on the basis of the Cassie-Baxter equation. The locust and moth wing surfaces are composed of naturally hydrophobic materials, but exhibit different complex wettability. The locust wing surface is of extremely high adhesion (sliding angle $>180^{\circ}$ ) and superhydrophobicity (contact angle $150.8 \sim 156.8^{\circ}$ ), while the moth wing surface is of low adhesion (sliding angle $1 \sim 5^{\circ}$ ) and superhydrophobicity (contact angle 150.2 154.1 ${ }^{\circ}$ ). The complex wettability of the wing surfaces ascribes to the cooperative effect of material element and structural element. The locust and moth wings can be potentially used as biomimetic templates for design and preparation of novel functional interface and no-loss microfluidic transport channels.
\end{abstract}

Keywords: Micro-morphology, Hydrophobicity, Adhesion, Insect, Model.

\section{Introduction}

The interfacial material with special wettability and function is attracting more and more attention due to valuable theoretical importance and application potential in industrial and domestic fields [1]. The representative states of a droplet on a hydrophobic surface include Wenzel state, Cassie state, and Wenzel-Cassie transitional state [2]. In recent years, a lot of researches have been focused on lotus leaf, on which a droplet displays a special Cassie state called "lotus state" (low adhesive superhydrophobicity) [3]. However, little attention has been paid to another special contact state called "Gecko state" (high adhesive superhydrophobicity) [4]. The superhydrophobic material with high adhesion can be used as "mechanical hand" in no-loss microfluidic transport [5]. In this work, the hydrophobicity, adhesion, chemical composition and microtexture of the locust and moth wing surfaces were comparatively investigated. The results may bring interesting insights into design of micro-controllable superhydrophobic surface and fabrication of smart interfacial materials.

\section{Materials and Methods}

\subsection{Materials}

The specimens of the locust (ten species) and moth (ten species) were collected in Changchun City, Jilin City, Harbin City and Dalian City of northeast China. The wings were cleaned, desiccated and flattened, then cut into $5 \mathrm{~mm} \times 5 \mathrm{~mm}$ pieces from the remigium (locust) and the discal cell (moth). The distilled water for measurements of CA and sliding angle (SA) was purchased from Tianjin Pharmaceuticals Group Co. Ltd., China. The volume of water droplets was $5 \mu$ l.

\subsection{Methods}

After gold coating by an ion sputter coater (Hitachi E-1045, Japan), the wing pieces were observed and photographed by a SEM (Hitachi SU8010, Japan). A video-based CA measuring system (DataPhysics OCA20, Germany) was used to measure the CA of water droplet on the wing surface by sessile drop method at ambient temperature of $25 \pm 1{ }^{\circ} \mathrm{C}$. The water SA was measured in the direction 
from the wing basal to the wing terminal end. The chemical composition of the wing surface was analyzed by means of FT-IR (Nicolet FT-IR200, USA).

\section{Results and Discussion}

\subsection{The Superhydrophobicity of the Wing Surfaces}

The wing surfaces of the ten locust species and the ten moth species display superhydrophobicity. The range of CA on the locust wing is $150.8 \sim 156.8^{\circ}$, the average is $153.6^{\circ}$. The range of CA on the moth wing is $150.2 \sim 154.1^{\circ}$, the average is $152.4^{\circ}$ (Table 1 ).

Table 1 The CA and SA of water droplet on the locust and moth wing surfaces

\begin{tabular}{|c|c|c|c|c|}
\hline & \multirow{2}{*}{ Species } & \multicolumn{2}{|c|}{$\mathrm{CA}\left(^{\circ}\right)$} & \multirow{2}{*}{ Measured SA $\left(^{\circ}\right)$} \\
\hline & & Measured CA & Predicted CA & \\
\hline \multirow{11}{*}{ Locust } & Arcyptera coreana & 153.9 & 154.2 & $>180$ \\
\hline & Chorthippus aethalinus & 151.6 & 150.7 & $>180$ \\
\hline & Chorthippus fallax & 155.2 & 155.4 & $>180$ \\
\hline & Dasyhippus barbipes & 156.5 & 160.1 & $>180$ \\
\hline & Euchorthippus fusigeniculatus & 151.4 & 149.3 & $>180$ \\
\hline & Gomphocerus rufus & 150.8 & 151.5 & $>180$ \\
\hline & Oedaleus infernalis & 153.8 & 156.0 & $>180$ \\
\hline & Omocestus haemorrhoidalis & 151.7 & 154.7 & $>180$ \\
\hline & Oxya chinensis & 156.8 & 154.6 & $>180$ \\
\hline & Podismopsis angustipennis & 154.2 & 154.2 & $>180$ \\
\hline & Average & 153.6 & 154.1 & $>180$ \\
\hline \multirow{11}{*}{ Moth } & Calamotropha paludella & 153.5 & 153.8 & 3 \\
\hline & Calothysanis comptaria & 152.7 & 154.6 & 2 \\
\hline & Celyphoides cespitanus & 151.4 & 155.1 & 3 \\
\hline & Clepsis strigana & 150.2 & 154.3 & 4 \\
\hline & Cnidocampa flavescens & 150.9 & 151.8 & 1 \\
\hline & Epiblema foenella & 153.4 & 157.1 & 1 \\
\hline & Eucosma metzneriana & 154.1 & 152.5 & 3 \\
\hline & Iotaphora admirabilis & 152.2 & 151.8 & 2 \\
\hline & Pandemis dumetana & 153.6 & 152.5 & 5 \\
\hline & Parasa sinica & 152.3 & 151.7 & 3 \\
\hline & Average & 152.4 & 153.5 & 3 \\
\hline
\end{tabular}

\subsection{The Opposite Adhesive Performance of the Wing Surfaces}

The water droplet displays extremely high adhesion on the locust wing. The droplet does not leave the locust wing at any angle of inclination, even verticalized or inverted. As a contrast, the water droplet displays low adhesion on the moth wing, the water SA is small $\left(1 \sim 5^{\circ}\right)$ (Table 1$)$.

\subsection{The Wetting Mechanism of the Wing Surfaces}

According to the FT-IR spectra, the locust wing surface is a waxy layer composed mainly of long chain hydrocarbon, tallate and fatty-acid alcohol. The main composition of the moth wing surface is chitin, protein and fat (Fig. 1). The locust and moth wing surfaces are both composed of naturally hydrophobic materials.
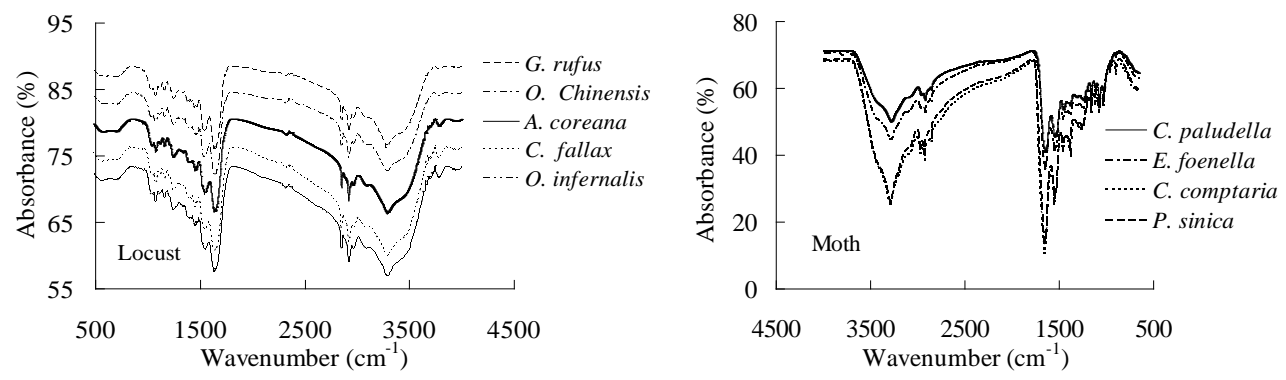

Fig. 1 FT-IR spectra of the wing surfaces 
However, the hydrophobic material alone can not make the wing surfaces achieve superhydrophobicity. Both the locust and the moth wing surfaces exhibit multiple-dimensional micro/nano structures. On the locust wing surface, the vein grids constitute the primary structure [Fig. 2(a)], the micrometric pillar gibbosities constitute the secondary structure [Fig. 2(b)], the nano corrugations between the pillar gibbosities constitute the tertiary structure [Fig. 2(c)]. On the moth wing, the micrometric scales constitute the primary structure [Fig. 2(d)], the submicro longitudinal ridges and horizontal bridges on the scales constitute the secondary structure [Fig. 2(e)], the nano stripes on the longitudinal ridges and horizontal bridges constitute the tertiary structure [Fig. 2(f)].

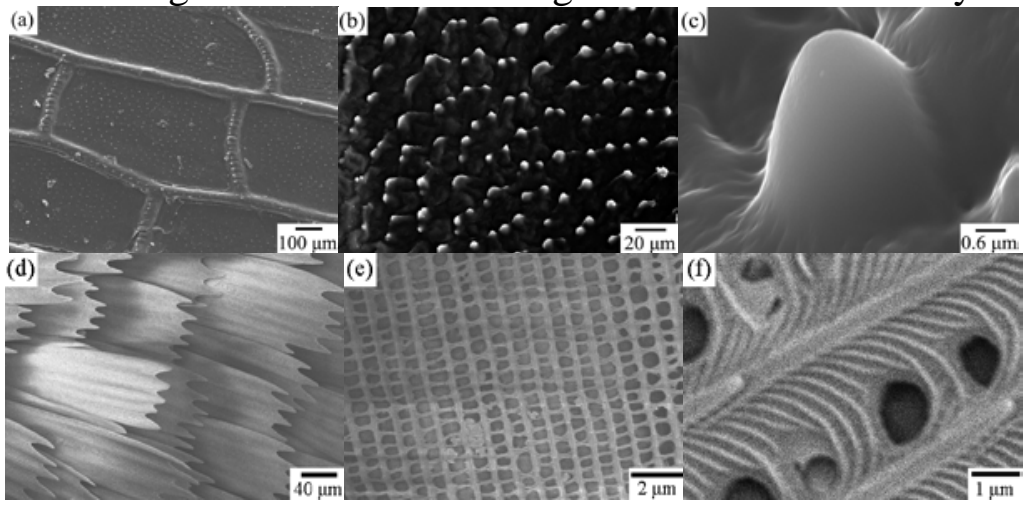

Fig. 2 The hierarchical microstructure of the locust and moth wing surfaces (SEM)

(a) Primary structure (locust); (b) Secondary structure (locust); (c) Tertiary structure (locust); (d)

Primary structure (moth); (e) Secondary structure (moth); (f) Tertiary structure (moth).

The spacing between the micrometric gibbosities on the locust wing (averagely $14.12 \mu \mathrm{m}$ ) is 6.0 times of that on the moth wing (averagely $2.28 \mu \mathrm{m}$ ). The density of the micrometric gibbosity on the locust wing is far smaller than that on the moth wing. On the locust wing, the air fraction (the percentage of liquid/vapor contact area) of water is 0.507 . The micrometric structure of the locust wing can be partially wetted by water. Relatively less air is trapped and sealed between water and the locust wing. As the water droplet is removed from the locust wing surface, negative pressure is produced due to the exchange of confined air, so high adhesive force is induced [5]. On the moth wing, the air fraction of water is 0.881 , which is much bigger than that on the locust wing. The water droplet stands on the tips of the submicro longitudinal ridges, much air is left under the droplet. The solid-liquid-gas triple contact lines (TCL) are expected to be contorted and unstable. The moth wing surface displays low adhesive superhydrophobicity.

\subsection{The Models for Hydrophobicity on the Wing Surfaces}

The locust and moth wing surfaces are rough, superhydrophobic and heterogeneous. A composite contact is formed between the droplet and the surface. Thus, the contact behavior can be expressed by the Cassie-Baxter equation:

$$
\cos \theta_{c}=\phi_{s} \cos \theta_{e}+\phi_{s}-1
$$

where $\theta_{c}$ is the apparent CA of a droplet on a composite surface, $\varnothing_{s}$ is the area fraction of solid $\left(0<\emptyset_{s}<1\right), \theta_{e}$ is the intrinsic CA of a droplet on an ideal flat surface $\left(105^{\circ}\right.$ and $95^{\circ}$ for the locust and moth wing, respectively). Fig. 3(a) shows the contact state of water on the locust wing. The parameters $r, h$, and $d$ represent the radius, height and spacing of the pillar gibbosity, respectively.
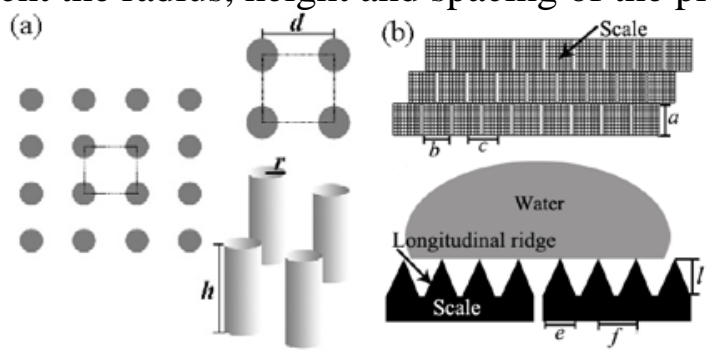

Fig. 3 The microstructural models for hydrophobicity on the wing surfaces. (a) Locust; (b) Moth. 
In this case:

$$
\phi_{s}=\pi r^{2} / d^{2}
$$

For the moth wing, Eq. (1) can be modified for the theoretical (predicted) CA $\left(\theta_{t}\right)$ :

$$
\cos \theta_{t}=\sqrt{\frac{4 l^{2}}{e^{2}}+1} * \frac{b e}{c f} * \cos \theta_{e}+\frac{b e}{c f}-1
$$

where the parameters $b, c$ represent the width and the spacing of the scale, respectively; $l, e$, and $f$ represent the height, width and spacing of the longitudinal ridge, respectively [Fig. 3(b)].

Based on Eqs. (1), (2) and (3), the predicted CAs on the locust and moth wing surfaces were calculated (Table 1). Taking predicted CAs as independent variable $y^{*}$, measured CAs as dependent variable $y$, the degree of fitting was judged as follows:

$$
\begin{aligned}
Q & =\sum\left(y-y^{*}\right)^{2} \\
R_{\text {New }} & =1-\left(Q / \sum y^{2}\right)^{1 / 2}
\end{aligned}
$$

where $Q$ is the sum of square of deviations, $R_{\mathrm{New}}$ is the coefficient of determination in nonlinear regression equation. The calculated $R_{\mathrm{New}}$ values are $0.941 \sim 0.962$ for the ten locust species, and $0.915 \sim 0.943$ for the ten moth species. There is no significant difference between the measured CAs and the predicted CAs, demonstrating the structural models for hydrophobicity accord well with the Cassie-Baxter equation.

\section{Conclusions}

The locust and moth wing surfaces are composed of naturally hydrophobic materials, and possess hierarchical micro-morphology. The locust wing surface is of high adhesive superhydrophobicity (CA $150.8 \sim 156.8^{\circ}, \mathrm{SA}>180^{\circ}$ ), while the moth wing surface is of low adhesive superhydrophobicity (CA $150.2 \sim 154.1^{\circ}$, SA $1 \sim 5^{\circ}$ ). The distinct complex wettability of the locust and the moth wing is induced by the different microtextures. The cooperative effect of hydrophobic material and rough microstructure leads to the special wettability of the wing surfaces. This work promotes our understanding of wetting mechanism of bio-surfaces, and may bring interesting insights for biomimetic preparation of novel interfacial material with multi-functions.

\section{Acknowledgments}

This work was financially supported by the National Natural Science Foundation of China (Grant NO. 31671010), the Innovative Program for Postgraduate Students of Changchun Normal University (Grant NO. cscxy2015007, cscxy2017003, cscxy2017006) and the Innovative and Entrepreneurship Program for Undergraduate Students of Jilin Province (201610205079, 201610205014). Dr. Prof. Gang Sun is the corresponding author of this paper.

\section{References}

[1] Y. Fang, G. Sun, Q. Cong, G.H. Chen, Effects of methanol on wettability of the non-smooth surface on butterfly wing, J. Bion. Engi. 5 (2008) 127-133.

[2] N.A. Patankar, On the modeling of hydrophobic contact angles on rough surfaces, Langmuir 19 (2003) 1249-1253.

[3] Y. Fang, G. Sun, T.Q. Wang, Q. Cong, Hydrophobicity mechanism of non-smooth pattern on surface of butterfly wing, Chin. Sci. Bull. 52 (2007) 711-716.

[4] M.H. Jin, X.J. Feng, L. Feng, T.L. Sun, J. Zhai, T.J. Li, L. Jiang, Superhydrophobic aligned polystyrene nanotube films with high adhesive force, Adv. Mater. 17 (2005) 1977-1981.

[5] L. Feng, Y.A. Zhang, J.M. Xi, Y. Zhu, N. Wang, F. Xia, L. Jiang, Petal effect: A superhydrophobic state with high adhesive force, Langmuir 24 (2008) 4114-4119. 